\title{
DESAIN PENGENDALI DENGAN UMPAN BALIK OUTPUT UNTUK SISTEM HIBRID MELALUI PENDEKATAN MARKOVIAN JUMP SYSTEM
}

\author{
Asep Najmurrokhman, Een Taryana, dan Ahmad Daelami \\ Jurusan Teknik Elektro, Fakultas Teknik, Universitas Jenderal Achmad Yani, Cimahi, 40533 \\ E-mail:asepnajmu@yahoo.com
}

\begin{abstract}
Abstrak
Sistem hibrid adalah sistem yang menggabungkan dinamika sistem yang kontinyu dengan diskrit dalam satu kerangka yang utuh. Dewasa ini, sistem hibrid hampir ditemukan dalam setiap aplikasi sistem kendali. Salahsatu bentuk khas sistem tersebut berupa subsistem kontinyu yang terdiri dari aktuator, plant dan sensor dikendalikan oleh subsistem pengendali digital misalnya mikrokontroler. Makalah ini menguraikan tentang desain pengendali dengan umpan balik output untuk sistem hibrid yang dimodelkan dengan Markovian Jump System (MJS). Dalam MJS, sistem terdiri dari subsistem dengan karaketeristik tertentu yang masing-masing menyatakan kondisi sistem dengan kondisi operasi yang berbeda-beda. Dinamika sistem keseluruhan ditunjukkan dengan adanya proses melompat (jump) dari satu subsistem ke subsistem lain. Pemodelan dengan MJS mengakomodasi sifat stokastik dari perpindahan subsistem. Dengan demikian, pengendali yang dirancang harus mampu menghasilkan tujuan pengendalian yang memenuhi untuk seluruh subsistem yang ada dalam sistem tersebut. Hasil utama dalam makalah ini berupa formula pertidaksamaan matriks linier untuk mencari pengendali yang memenuhi kestabilan sistem lingkar tertutupnya. Sebuah simulasi numerik diberikan untuk memperlihatkan keefektifan dari formulasi yang diusulkan dalam makalah ini.
\end{abstract}

\begin{abstract}
Output Feedback Controller Design for A Class of Hybrid Systems via Markovian Jump System Approach.

A Hybrid System is a kind of system which unifies continuous-time and discrete-time dynamical system in a framework. Nowadays, a hybrid system is ubiquitous in mostly application of control systems. A typical hybrid system comprises continuous-time subsystems such as actuator, plants, and sensor are controlled by digital controller such as microcontroller. This paper describes on output feedback controller design for a class of hybrid systems which modeled by Markovian Jump System (MJS). In MJS, the whole system dynamics is characterized by a stochastically jumping process from a subsystem to the others. A designed controller should satisfy a certain performance for the whole-system. The main result reported in this paper includes a linear matrix inequality formulation to find a controller in order to attain the stability of closed loop system. A numerical example is shown to describe the effectiveness of a method proposed in this paper.
\end{abstract}

Keywords: hybrid systems, markovian jump systems, output feedback, linear matrix inequalities

\section{Pendahuluan}

Sistem hibrid adalah sistem dinamis yang tersusun oleh komponen dengan perilaku kontinyu dan diskrit dan kedua subsistem tersebut saling berinteraksi membentuk perilaku sistem keseluruhan [1]. Dalam hal aplikasi, sistem hibrid muncul saat kita mengatur suatu proses yang kontinyu melalui penggunaan pengendali yang bersifat diskrit, misalnya menggunakan mikrokontroler. Perspektif sistem ini juga tampak dalam implementasi pengaturan beberapa mesin listrik secara serempak melalui mekanisme pemilihan mesin listrik yang beroperasi atas dasar efisiensi dan pertimbangan lainnya. Salahsatu pertimbangan tersebut berupa perubahan kondisi operasi sehingga harus terjadi pemilihan ini. Dalam 
beberapa referensi, kendaraan dengan sumber penggerak ganda melalui mekanisme pengaturan bahan bakar dan sumber listrik atau pembangkit listrik dengan menggunakan sumber energi yang bervariasi kadang-kadang disebut sebagai sistem hibrid [2,3,4]. Goncalves, et al [2] membahas sistem hibrid dalam implementasi sistem penyedia air untuk keperluan industri besar dengan sumber energi listriknya dihasilkan dengan mengatur tiga sumber yaitu transmisi jala-jala (grid), mikrohidro, dan turbin angin. Borhan, et al [3] mendiskusikan perspektif sistem hibrid dalam kendaraan modern berupa pengendalian sumber energi gerak kendaraan dari bahan bakar dan energy listrik. Sementara itu, Delimustafic, et al [4] menjelaskan aspek pemodelan dan pengendalian sistem hibrid dalam penyediaan sumber energi terbarukan. Artunes, et al [5] menerapkan perspektif sistem hibrid dalam networked control systems, yaitu sebuah sistem kendali yang memanfaatkan jaringan komunikasi sebagai bagian dari lingkar kendali.

Untuk mendapatkan gambaran utuh tentang sistem hibrid, model matematika yang dibangun harus menggabungkan dinamika sistem kontinyu dengan dinamika sistem diskrit. Bentuk sistem hibrid dalam aplikasi sistem kendali muncul ketika pembentukkan sinyal kendali yang kontinyu dilakukan dengan mengikuti mekanisme tertentu secara diskrit. Misalnya dalam sistem tersebut, pengendali yang dirancang bergantung kepada tiga kondisi operasi dalam subsistem kontinyu kemudian dirancang bagaimana mekanisme pemilihan tiga buah pengendali tersebut dengan menerapkan operasi saklar secara diskrit. Dalam kasus tersebut, mekanisme sistemnya bergantung kepada operasi perpindahan saklar, sehingga beberapa peneliti kadang-kadang memberi istilah sistem hibrid dengan switched system $[6,7,8]$.

Salahsatu pendekatan dalam memodelkan sistem hibrid adalah Markovian Jump System (MJS). Dalam model tersebut, matriks-matriks dalam representasi ruang keadaan sistemnya bergantung kepada state dalam rantai Markovnya. State pada rantai Markov berupa anggota dari himpunan bilangan bulat. Gambar 1 memperlihatkan contoh rantai Markov dengan dua variabel state. Variabel tersebut menggambarkan keadaan saat terjadi tegangan jatuh dan kondisi normal pada sistem transmisi tenaga listrik. Variabel tersebut juga dapat melukiskan kondisi "mati" atau "hidup" suatu pengkondisi suhu ruangan.

Variabel state dalam rantai Markov sebuah sistem hibrid seringkali disebut sebagai mode sistem. Dengan demikian, apabila sebuah sistem hibrid memiliki dua variabel state seperti pada gambar 1 , maka dinamika sistemnya memiliki dua mode.
Dalam sistem tersebut, saat mode satu dinamika sistemnya berperilaku mengikuti sistem kontinyu mode satu.

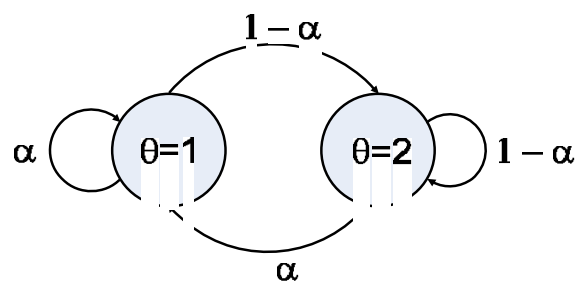

Gambar 1. Rantai Markov dengan dua state

Apabila ada kondisi tertentu sehingga mode sistem berubah menjadi mode dua, maka dinamika sistemnya mengikuti sistem kontinyu mode dua, dan seterusnya. Dalam kasus tersebut, terlihat bahwa dinamika sistem keseluruhan berlangsung sebagai urutan perpindahan atau transisi antar mode dalam sistem. Karena transisi antar mode bersifat acak, maka atribut lain yang muncul dalam rantai Markov adalah probabilitas transisi antar mode. Nilai probabilitas transisi ditentukan berdasarkan sifat keacakan dari parameter dalam proses sistem hibrid tersebut. Apabila transisi antar mode dalam sistem hibrid dimodelkan dengan rantai Markov yang memiliki dua state seperti pada gambar 1, maka $\alpha$ menandai probabilitas transisi dari mode 1 ke mode 1 atau dari mode 2 ke mode 1, sedangkan $(1-\alpha)$ adalah probabilitas transisi dari mode $1 \mathrm{ke}$ mode 2 atau dari mode 2 ke mode 2 .

\section{Markovian Jump System (MJS)}

Sebuah MJS dipandang memberikan representasi yang baik dalam memodelkan sistem yang memiliki parameter di dalamnya. Parameter sistem diantaranya kondisi operasi sistem, perubahan nilai parameter yang tiba-tiba, perubahan lingkungan tempat sistem berada, dan lain-lain [9].

Tinjau diagram blok sistem dengan umpan balik seperti pada gambar 2 dengan $G p$ menyatakan blok plant yang diperumum dan $K$ menandai pengendali yang dirancang.

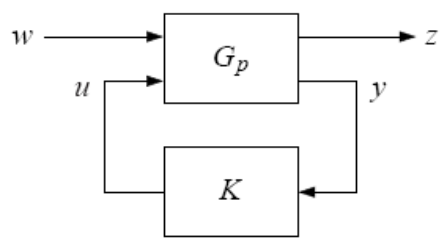

Gambar 2. Sistem berumpan balik

Secara umum, persamaan ruang keadaan dalam bentuk waktu kontinyu dengan state rantai Markov $\theta$ diberikan oleh persamaan berikut: 


$$
G_{p}:\left\{\begin{array}{c}
\dot{x}=A(\theta(t)) x(t)+B_{1}(\theta(t)) u(t)+B_{2}(\theta(t)) w(t) \\
y(t)=L(\theta(t)) x(t)+H(\theta(t)) w(t) \\
z(t)=C(\theta(t)) x(t)+D(\theta(t)) u(t) \\
x(0)=x_{0}, \theta(0)=\theta_{0}
\end{array}\right.
$$

dengan $x(t)$ menyatakan variabel keadaan sistem, $u(t)$ adalah input kendali, $w(t)$ menandai deretan derau (noise) yang masuk ke dalam sistem, $y(t)$ adalah variabel output terukur yang disediakan untuk pengendali, dan $z(t)$ menyatakan output sistem. Matriks-matriks sistemnya bergantung kepada state dari rantai Markov $\theta(t)$ yang nilainya berada dalam himpunan berhingga $\aleph \equiv\{1, \ldots, N\}$. Distribusi awal $\theta_{0}$ ditandai dengan $v=\left\{v_{1}, \ldots, v_{N}\right\}$ dan matriks probabilitas transisinya ditandai dengan $\mathbf{P}=\left[p_{i j}\right]$. Dengan demikian, mode sistemnya direpresentasikan oleh state $\theta(t)$.

Dalam konteks penelitian yang dilaporkan dalam makalah ini, model MJS dituliskan dalam bentuk berikut:

$$
G_{p}\left\{\begin{array}{c}
\dot{x}(t)=A(\theta(t)) x(t)+B(\theta(t)) u(t) \\
y(t)=C_{y}(\theta(t)) x(t) \\
x(0)=x_{0} ; \theta(0)=\theta_{0}
\end{array}\right.
$$

dengan $x(t) \in \mathrm{R}^{\mathrm{n}}, x_{0} \in \mathrm{R}^{\mathrm{n}}, u(t) \in \mathrm{R}^{\mathrm{m}}, y(t) \in \mathrm{R}^{\mathrm{p}}$ dan $\theta(t) \in \mathcal{N}$ seperti yang disebutkan pada bagian sebelumnya. Proses Markov $\{\theta(t), t \geq 0\}$ selain berada dalam suatu himpunan berhingga $\aleph$ juga menjelaskan perpindahan (jump) antara mode yang berbeda. Probabilitas transisi dari satu mode ke mode lainnya diberikan dalam bentuk berikut:

$$
p_{i j}=\operatorname{Prob}\{\theta(\mathrm{t}+\mathrm{h})=j \mid \theta(t)=i\}=\left\{\begin{array}{c}
\lambda_{i j} h+o(h) \\
1+\lambda_{i i} h+o(h)
\end{array}\right.
$$

Parameter $\lambda_{i j}$ menyatakan laju transisi dari mode $i$ ke mode $j$ dengan $\lambda_{i j} \geq 0$ saat $i \neq j$ dan $\lambda_{i i}=-\sum_{j=1, i \neq j}^{N} \lambda_{i j}$ serta $o(h)$ menandai suku orde tinggi yang memenuhi $\lim _{h \rightarrow 0} \frac{o(h)}{h}=0$. Boukas [10] menurunkan kondisi kestabilan untuk sistem tanpa input $(u(t)=0)$ dalam teorema berikut.

Teorema 1. Sebuah sistem (2) tanpa input bersifat stabil apabila terdapat matriks-matriks simetrik definit positif $P_{i}$ yang memenuhi pertidaksamaan matriks linier berikut:

$$
A_{i}^{T} P_{i}+P_{i} A_{i}+\sum_{j \neq i} \lambda_{i j} P_{j}<0, \forall i \in \aleph
$$

dengan notasi $A_{i}=\left.A\right|_{\theta(t)=i}$.

\section{Perancangan Pengendali}

Ada dua cara menggunakan umpan balik dalam perancangan pengendali, yaitu umpan balik keadaan dan umpan balik output. Dalam umpan balik keadaan, perancang mengasumsikan seluruh keadaan plant diketahui setiap saat dari data sensor. Asumsi tersebut seringkali tidak terpenuhi, karena keterbatasan kualitas sensor yang digunakan, penempatan sensor yang tidak memadai, atau tidak adanya sensor untuk variabel keadaan tersebut. Dalam hal demikian, pengendali yang dirancang memanfaatkan data output sebagai umpan balik sistem lingkar tertutupnya.

Dalam makalah ini, struktur pengendali yang dirancang memiliki representasi ruang keadaan dalam bentuk berikut:

$$
K:\left\{\begin{array}{c}
\dot{x}_{c}(t)=K_{A}(\theta(t)) x_{c}(t)+K_{B}(\theta(t)) y(t) \\
u(t)=K_{C}(\theta(t)) x_{c}(t) \\
x_{c}(0)=0
\end{array}\right.
$$

dengan $x_{c}(t) \in \mathrm{R}^{\mathrm{n}}$ dan $y(t) \in \mathrm{R}^{\mathrm{p}}$ masing-masing menyatakan variabel keadaan pengendali dan sinyal output yang diperoleh dari data pengukuran. Dari bentuk (5), perancangan pengendali berkaitan dengan penentuan nilai-nilai penguatan $K_{A}, K_{B}$, dan $K_{C}$ yang memenuhi tujuan pengendalian. Augmentasi persamaan (3) dan (5) menghasilkan representasi ruang keadaan baru sebagai berikut:

$$
\left\{\begin{array}{c}
\dot{\eta}(t)=\left[\begin{array}{cc}
A(\theta(t)) & B(\theta(t)) \\
K_{B}(\theta(t)) C_{y}(\theta(t)) & K_{A}(\theta(t))
\end{array}\right] \eta(t) \\
\eta(0)=\left[\begin{array}{c}
x_{0} \\
0
\end{array}\right]
\end{array}\right.
$$

dengan $\eta(t)=\left[\begin{array}{c}x(t) \\ x_{c}(t)\end{array}\right]$. Dengan mendefinisikan matriks berikut

$$
\tilde{A}(\theta(t))=\left[\begin{array}{cc}
A(\theta(t)) & B(\theta(t)) \\
K_{B}(\theta(t)) C_{y}(\theta(t)) & K_{A}(\theta(t))
\end{array}\right]
$$

dan menerapkan teorema 1 , sistem lingkar tertutup (6) bersifat stabil apabila terdapat matriks simetrik definit positif $P_{i}$ yang memenuhi pertidaksamaan matriks linier berikut:

$$
\widetilde{A}_{i}^{T} P_{i}+P_{i} \widetilde{A}_{i}+\sum_{j \neq i} \lambda_{i j} P_{j}<0, \forall i \in \aleph
$$

Dimensi matriks $P_{i}$ bersesuaian dengan matriks (7). Dengan menerapkan hasil yang diturunkan oleh Boukas [10], teorema berikut merangkum cara memperoleh pengendali dengan umpan balik output (5) yang menghasilkan kestabilan lingkar tertutup untuk sistem (2).

Teorema 2. Sistem lingkar tertutup (6) bersifat stabil untuk seluruh mode sistem, apabila terdapat matriks-matriks simetrik definit positif $X_{i}$ dan $Y_{i}$ serta matriks-matriks $\Xi_{B}$ dan $\Xi_{C}$ dengan dimensi 
bersesuaian yang memenuhi pertidaksamaan matriks linier berikut:

$$
\begin{gathered}
{\left[\begin{array}{cc}
\Psi_{i} & S_{i}(Y) \\
S_{i}^{T}(Y) & -\Phi_{i}(Y)
\end{array}\right]<0} \\
X_{i} A_{i}+\Xi_{B i} C_{y i}+A_{i}^{T} X_{i}+C_{y i}^{T} \Xi_{B i}^{T}+\sum_{j \neq i} \lambda_{i j} X_{j}<0
\end{gathered}
$$

$$
\left[\begin{array}{cc}
Y_{i} & I \\
I & X_{i}
\end{array}\right]>0(10)
$$

dengan

$$
\begin{aligned}
& S_{i}(Y)=\left\lfloor\sqrt{\lambda_{i 1}} Y_{i}, \cdots, \sqrt{\lambda_{i i-1}} Y_{i}, \sqrt{\lambda_{i i+1}} Y_{i}, \cdots \sqrt{\lambda_{i N}} Y_{i}\right\rfloor \\
& \Phi_{i}(Y)=\operatorname{diag}\left[Y_{1}, \cdots Y_{i-1}, Y_{i+1}, \cdots, Y_{N}\right] \\
& \text { dan notasi } A_{i}=\left.A\right|_{\theta(t)=i} .
\end{aligned}
$$

Apabila tiga buah pertidaksamaan matriks linier (8)-(10) memiliki solusi, maka pengendali (5) dikonstruksi dengan masing-masing nilai matriks penguatannya sebagai berikut:

$$
\begin{aligned}
K_{A i}= & {\left[X_{i}-Y_{i}^{-1}\right]^{-1}\left[A_{i}^{T}+X_{i} A_{i} Y_{i}+X_{i} B_{i} \Xi_{C i}+\Xi_{B i} C_{y i} Y_{i}\right.} \\
& \left.\quad+\sum_{j=1}^{N} \lambda_{i j} Y_{j}^{-1} Y_{i}\right] Y_{i}^{-1} \\
K_{B i}= & {\left[Y_{i}^{-1}-X_{i}\right]^{-1} \Xi_{B i} } \\
K_{C i}= & \Xi_{C i} Y_{i}^{-1}
\end{aligned}
$$

Selanjutnya, sebuah simulasi numerik dibuat untuk memperlihatkan keefektifan dari algoritma yang diusulkan dalam merancang pengendali. Representasi ruang keadaan untuk kasus yang diambil berbentuk sebagai berikut:

$$
\begin{gathered}
A_{1}=\left[\begin{array}{cc}
1 & -0,5 \\
0,1 & 1
\end{array}\right] ; \quad B_{1}=\left[\begin{array}{ll}
1 & 0 \\
0 & 1
\end{array}\right] ; \quad C_{y 1}=\left[\begin{array}{ll}
1 & 0 \\
0 & 1
\end{array}\right] \\
A_{2}=\left[\begin{array}{cc}
-0,2 & -0,5 \\
0,5 & -0,25
\end{array}\right] ; \quad B_{2}=\left[\begin{array}{ll}
1 & 0 \\
0 & 1
\end{array}\right] ; \quad C_{y 2}=\left[\begin{array}{ll}
1 & 0 \\
0 & 1
\end{array}\right]
\end{gathered}
$$

dengan indeks 1 dan 2 menyatakan mode dalam sistem tersebut. Respon lingkar terbuka untuk masing-masing mode tersebut diperlihatkan dalam gambar 3 dan 4 .

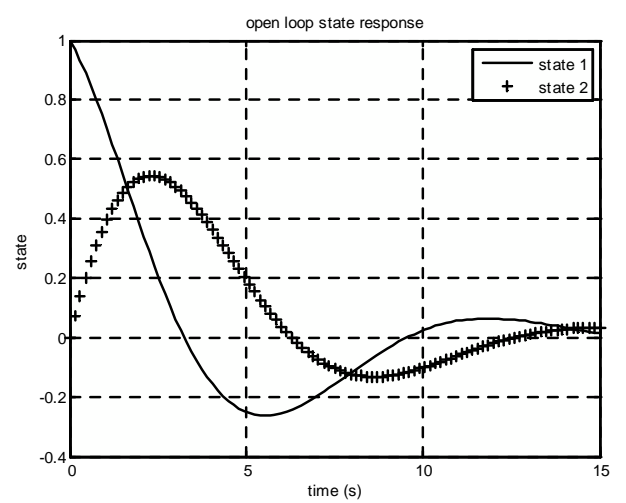

Gambar 3. Respon lingkar terbuka mode 1
Terlihat bahwa mode 1 bersifat tidak stabil, sehingga sistem keseluruhan bersifat tidak stabil. Asumsikan perpindahan mode sistem terjadi dengan laju transisi antar mode mengikuti matriks berikut:

$$
\left[\begin{array}{ll}
\lambda_{11} & \lambda_{12} \\
\lambda_{21} & \lambda_{22}
\end{array}\right]=\left[\begin{array}{cc}
-2 & 2 \\
3 & -3
\end{array}\right]
$$

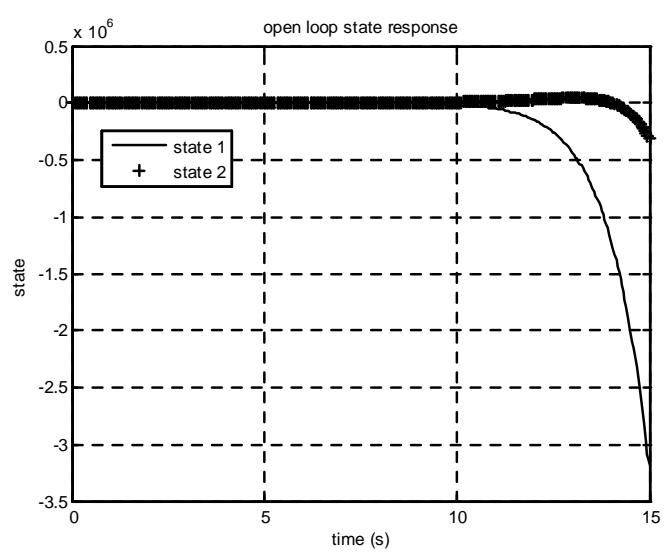

Gambar 4. Respon lingkar terbuka mode 2

Dengan memecahkan pertidaksamaan matriks linier (8)-(10) menggunakan perangkat lunak standar, seperti Robust Control Toolbox dalam MATLAB [11] atau Sedumi [12], diperoleh matriks-matriks berikut:

$$
\begin{aligned}
& X_{1}=\left[\begin{array}{cc}
155,3339 & 0,0000 \\
0,0000 & 155,3339
\end{array}\right], \\
& X_{2}=\left[\begin{array}{cc}
156,7142 & -0,0000 \\
-0,0000 & 156,7142
\end{array}\right] \\
& Y_{1}=\left[\begin{array}{ll}
85,5704 & -0,0000 \\
-0,0000 & 85,5704
\end{array}\right], Y_{2}=\left[\begin{array}{cc}
76,2129 & 0,0000 \\
0,0000 & 76,2129
\end{array}\right] \\
& \Xi_{B 1}=\left[\begin{array}{cc}
-240,2401 & 78,9301 \\
-16,7965 & -240,2401
\end{array}\right], \\
& \Xi_{B 2}=\left[\begin{array}{cc}
-50,1127 & -5,2440 \\
5,2440 & -42,2770
\end{array}\right] \\
& \Xi_{C 1}=\left[\begin{array}{cc}
-170,7 & 2513,7 \\
-2480 & -170,7
\end{array}\right], \\
& \Xi_{C 2}=\left[\begin{array}{cc}
-45,2177 & -5,8319 \\
5,8319 & -41,4071
\end{array}\right]
\end{aligned}
$$

Selanjutnya, matriks-matriks pengendali ditentukan dengan memasukkan nilai-nilai solusi di atas ke persamaan (11)-(13) sehingga diperoleh hasil berikut:

$$
\begin{aligned}
K_{A 1} & =\left[\begin{array}{cc}
-2,5413 & 29,3867 \\
-28,9867 & -2,5413
\end{array}\right], \\
K_{A 2} & =\left[\begin{array}{cc}
-1,1132 & -0,6100 \\
0,6100 & -1,0632
\end{array}\right]
\end{aligned}
$$


$K_{B 1}=\left[\begin{array}{cc}1,5467 & -0,5082 \\ 0,1081 & 1,5467\end{array}\right], K_{B 2}=\left[\begin{array}{cc}0,3198 & 0,0335 \\ -0,0335 & 0,2698\end{array}\right]$

$K_{C 1}=\left[\begin{array}{cc}-1,9946 & 29,7634 \\ -28,9764 & -1,9946\end{array}\right]$,

$K_{C 2}=\left[\begin{array}{cc}-0,5933 & -0,0765 \\ 0,0765 & -0,5433\end{array}\right]$

Untuk keperluan simulasi, transisi antar mode diperlihatkan dalam gambar 5 .

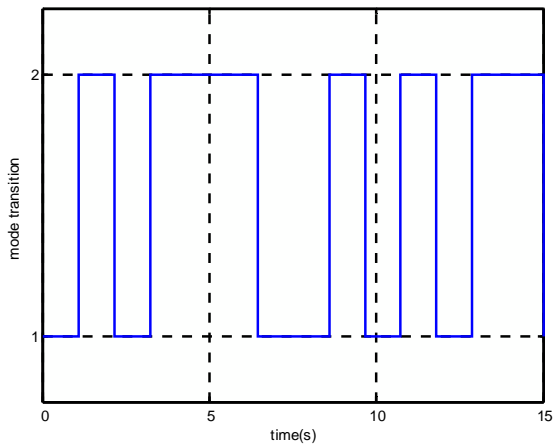

Gambar 5. Transisi mode

Hasil simulasi berupa respon keadaan lingkar tertutup yang diberikan pada gambar 6 memperlihatkan bahwa pengendali yang dirancang berhasil menstabilkan sistem lingkar tertutup secara keseluruhan.

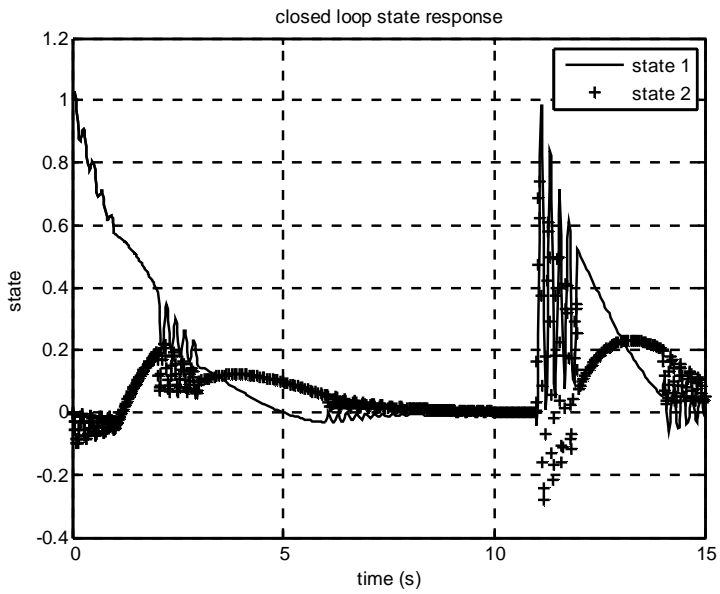

Gambar 6. Respon state lingkar tertutup

\section{Kesimpulan}

Telah diuraikan desain pengendali dengan umpan balik output untuk sistem hibrid yang dimodelkan dengan Markovian Jump System. Tujuan pengendalian yang ditinjau dalam makalah adalah stabilisasi sistem lingkar tertutup. Sebuah pengendali dapat diperoleh apabila terdapat solusi untuk tiga buah pertidaksamaan matriks linier. Selanjutnya, matriks-matriks pengendali ditentukan berdasarkan solusi tersebut. Hasil simulasi stabilisasi terhadap sistem dengan dua mode memperlihatkan pengendali yang dirancang mampu menstabilkan sistem lingkar tertutupnya. Penelitian selanjutnya yang dilakukan berupa penerapan kendali kokoh yang mempertimbangkan ketidakpastian parameter sistem atau gangguan eksternal.

\section{Daftar Acuan}

[1] J. Lunze and F. L. Lagarrigue (eds), Handbook of Hybrid Systems Control: Theory, Tools, Application, Cambridge University Press, 2009, p. 4.

[2] F. V. Goncalves, H. M. Ramos \& L. F. R. Reis, Hybrid energy system evaluation in water supply system energy production: neural network approach", Int. Journal of Energy and Environment vol. 1, no. 1, 2010, pp. 21-30.

[3] H. Borhan, et al., MPC-Based Energy Management of a Power-Split Hybrid Electric Vehicle, appear in IEEE Trans. on Control Systems Technology, 2011.

[4] D. Delimustafic, et al., "Model of a hybrid renewable energy system: Control, supervision and energy distribution", IEEE Int. Symposium on Industrial Electronics, 2730 June 2011, pp. 1081-1086.

[5] D. Artunes, J. P. Hespanha \& C. Silvestre, Volterra Integral Approach to Impulsive Renewal System: Application to Networked Contro, appear in IEEE Trans. on Automatic Control, 2012.

[6] M. S. Mahmoud, Delay-dependent dissipativity analysis and synthesis of switched delay systems, Int. Journal on Robust \& Nonlinear Control, vol. 1, no. 1, January 2011, pp. 1-20.

[7] J. Zhao \& D. Hill, Dissipativity Theory for Switched Systems, IEEE Trans. on Automatic Control, vol. 53, no. 4, April 2008, pp. 941953.

[8] K. Hirata \& J. P. Hespanha, L2-induced gains of switched systems and classes of switching signals, Proc. IEEE Conference on Decision and Control 15-17 December 2010, pp. 438442.

[9] O. L. V. Costa, et al, "Discrete-time Markov Jump Linear Systems", Springer-Verlag London, 2005, p. 1.

[10] E. K. Boukas, "Stochastic Switching Systems", Birkhauser Boston, 2006.

[11] The Mathworks Inc., Robust Control Toolbox for use with Matlab, 2001. 